\title{
Study on the Influencing Factors of College Students' Job Satisfaction Haochuan Lu
}

School of Management, Wuhan University of Technology, Wuhan, Hubei Province, 430070, China. 645154814@qq.com

\section{Keywords: Job satisfaction; Structural Equation Modeling; College graduates}

\begin{abstract}
A umber of college graduates increased year by year and the employment pressure is increasing. Through the literature analysis, the factors affecting the job satisfaction of college graduates is divided into three dimensions: family social capital, human capital and school support. This paper design relevant variables and use the questionnaire to collect data. On this basis, the paper do further research by structural equation modeling.
\end{abstract}

\section{Introduction}

The report of the eighteenth national congress of the CPC and the bulletin of third Plenary Session of the 18th CPC Central Committee proposed the "higher quality employment" and "enhance the stability of employment" and "improve college graduates focus on youth employment quality". Those shows that the party and the government in the past to pay more attention to the employment of college students based on the amount and begin to pay more attention to the quality of college students' employment. Therefore, in recent years, the domestic education and academic circles have paid more attention to the quality of College Students' employment. Job satisfaction is a micro index that reflects the quality of employment objectively. And it has also become the relevant content of academic research.

\section{Research Method and Assumptions}

Method. The structural equation model is adopted in this paper. The measurement equation is $\mathrm{x}=\Lambda \mathrm{x} \xi+\delta$ and $\mathrm{y}=\Lambda \mathrm{y} \eta+\varepsilon$, where $\mathrm{x}$ and $\mathrm{y}$ are exogenous variable vector and endogenous variable vector; " $\xi$ " is exogenous latent variables vector and " $\eta$ " is endogenous latent variables vector; " $\Lambda \mathrm{x}$ "refers to the relationship between exogenous index and exogenous latent variables; " $\Lambda$ " refers to the relationship between endogenous index and endogenous latent variables; " $\delta$ " and " $\varepsilon$ " is the error term, accordingly, that cannot be explained by the latent variable. The structural equation is $\eta=\beta \eta+\Gamma \xi+\zeta$, where, " $\eta$ " is endogenous latent variables and " $\xi$ " is exogenous latent variables, " $\beta$ " is the relation between endogenous latent variables; " $\Gamma$ " is effects of exogenous latent variables on endogenous latent variables, " $\zeta$ " is residual error of the structural equation.

Assumptions. The job satisfaction of university graduates is the result of the combination of many factors. The research on the influencing factors of university graduates' job satisfaction is mainly discussed in three dimensions [1]. Based on these three research dimensions, the hypotheses about the influencing factors of college students' job satisfaction are assumed:

\section{Hypothesis Family Social Capital Factor}

H1a: family social capital has a significant positive impact on human capital

H1b: family social capital has significant positive impact on school support

H1c: family social capital has a significant positive impact on job satisfaction

Hypothesis of Human Capital Factor

H2: human capital has a significant positive impact on job satisfaction

Hypothesis School Support Factor

H3a: school support has a significant positive impact on human capital

H3b: school support has a significant positive impact on job satisfaction 


\section{Model Design}

Selection of Measurement Variables. By reading a lot of literatures, according to summarize the influence of family social capital, human capital and school level employment satisfaction literature, measured variables to make three dimensions, designed the first draft of the questionnaire.

\section{Family Social Capital Variable}

The family social capital variables include family background, family income, parents' average education years, parents' age, parents' residence, parents' work departments and so on [2]. In this paper, three important indexes are selected again. Family social capital dimension:

\section{A1: Family Income A2: Parental Qualifications A3: Family location}

\section{Human Capital Variable}

Hongisto , from the student perspective, to study the function of human capital property, points out that when college students are learning in college, they will exercise and acquire abundant professional knowledge [3]. The practice ability and knowledge depend on the students themselves, and gradually formed their human capital. Pan, through the research, believe the concept of "students' human capital" is defined as the process of college students in education or training in an exclusive value accumulation, the value of college students individual, intelligence level, management ability and personal skills [4]. From here, the following three indexes are set up:

\section{B1: Student Work \\ B2: Social Practice \\ B3: Educational Background}

\section{School Support Variables}

Macdonald divided the school support factors into two variables: school type and school location [5]. According to the above literature, the following three measurement variables are selected:

\section{C1: School Level C2: Employment Guidance C3: School Location}

\section{Job Satisfaction Variables}

The National Science Foundation has conducted a national college graduate survey for a long period of time, involving job satisfaction surveys in the survey[6]. The employment results are divided into 9 specific items: salary, welfare, security, employment place, promotion opportunity, ability display, work intensity, independence and social contribution [7,8]. The three most important variables are selected from this paper:

\section{D1: Salary \\ D2: Work Location \\ D3: Ability to Play}

Model Establishment. In this paper, a questionnaire was designed according to measurement variables. And questionnaires were issued at 10 different levels of colleges and universities. Author Collected 211 valid questionnaires and analysis of statistical data, to verify that the sample data is consistent with the normal distribution; Through the test of data, the reliability and validity of the data are both good. On this basis, we establish the structural equation model (Figure 1).

The model in this study can be divided into structural model and measurement model. The most important task is to construct a structural model to determine all latent variables involved in the model. Before building an model, the relationship and function between variables should be determined first. Of course, this relationship and function need to be further verified before they can be known. This paper sets up 4 latent variables: family social capital, human capital, school support and job satisfaction. In the 4 latent variables, we based on the assumptions mentioned above, the "family social capital"(FSC), as exogenous latent variables, the "human capital"(HC), "school support"(SS) and "job satisfaction"(JS) as endogenous latent variables.

Figure 1. Structural Equation Model

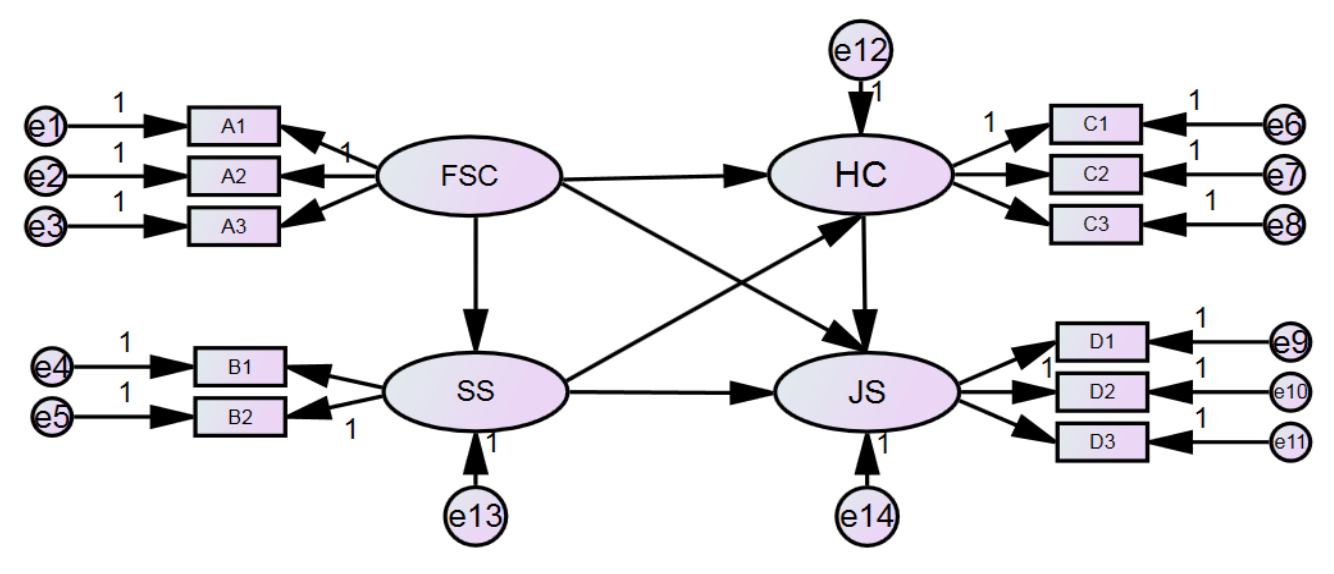


Model Checking. In the present model, the chi squared value is 157.429 , the degree of freedom is 38 , the ratio of the chi square to the degree of freedom is 4.413 , less than the critical value of 5, which conforms to the fitting standard of the model. The chi square value is easily affected by the number of samples and when the number of samples is large enough, the chi square value will be very large, so the chi square value only as a reference index to evaluate the degree of fitting, but not as a decisive index. Therefore, this paper uses GFI, NFI, CFI, IFI and other indicators that not to be affected by the sample size to evaluate the model's fitting degree. The empirical results are shown in table 1. As can be seen from the table, most of the indicators are within acceptable level, indicating that the model is well fitted.

Table 1 Fitness index Structural Equation Model,

\begin{tabular}{|c|c|c|c|}
\hline Index & The critical value & Test result data & Judgment \\
\hline$\chi^{2}$ & The smaller the better & $157.429(\mathrm{P}=0.000)$ & No \\
\hline$\chi^{2 / d f}$ & $<5$ & $157.429 / 38=4.413$ & Acceptable \\
\hline GFI & $>0.85$ & 0.881 & Acceptable \\
\hline NFI & $>0.85$ & 0.880 & Acceptable \\
\hline $\mathrm{CFI}$ & $>0.85$ & 0.905 & Good \\
\hline RMR & $<0.1$ & 0.059 & Acceptable \\
\hline RMSEA & $<0.1$ & 0.122 & Mediocre \\
\hline RFI & $>0.85$ & 0.826 & Mediocre \\
\hline IFI & $>0.85$ & 0.906 & Good \\
\hline TLI & $>0.85$ & 0.862 & Acceptable \\
\hline
\end{tabular}

Table 2 Path Coefficient of Structural Equation Model

\begin{tabular}{llllll}
\hline \hline Path & Estimate & S.E. & C.R. & P & Standardized Estimate \\
\hline SS $\leftarrow$ FSC & 0.299 & 0.096 & 3.117 & 0.002 & 0.269 \\
HC $\leftarrow$ FSC & 0.194 & 0.072 & 2.696 & 0.007 & 0.211 \\
HC $\leftarrow$ SS & 0.255 & 0.067 & 3.823 & $* * *$ & 0.307 \\
JS $\leftarrow$ HC & 0.094 & 0.090 & 1.043 & 0.297 & 0.091 \\
JS $\leftarrow$ SS & 0.152 & 0.080 & 1.901 & 0.057 & 0.177 \\
JS $\leftarrow$ FSC & 0.160 & 0.083 & 1.919 & 0.055 & 0.168 \\
\hline \hline
\end{tabular}

Result Analysis. According to table 2 model estimation results shown, the standardized path coefficient of family social capital to human capital of the is 0.211 ; The significance value is 0.007 , less than 0.01 . That is, at the $1 \%$ significant level, family social capital has a significant positive impact on human capital, and the H1a hypothesis is supported. The standardized path coefficient of family social capital to support the school is 0.269 ; The significance value is was 0.002 , less than 0.01 . That is, at the $1 \%$ significant level, family social capital has a significant positive impact on school support, and the H1b hypothesis is supported. The standardized path coefficient of family social capital to the job satisfaction was 0.168 ; The significance value is 0.055 , close to 0.05 . The data indicate the coefficient at the $5 \%$ significance level is not significant, but It can be considered that family social capital has positive influence on school support, just not significant. H1c hypothesis is close to being supported. The standardized path coefficient of human capital to the job satisfaction is 0.091; Significantly higher than 0.05, that is 0.297. The coefficient is not significant at the 5\% level, namely human capital to employment satisfaction has no significant effect. $\mathrm{H} 2$ hypothesis is not supported. The school support as independent variables, the school support to the standardized path coefficient of human capital is 0.307 , significantly less than 0.01 . The coefficient is significant at the $1 \%$ level, the school support has a significant positive impact on human capital, H3a hypothesis is supported. School support to the standardized path coefficient of employment the degree of satisfaction is 0.177 ; The significance value is 0.057 , close to 0.05 . The data indicate the coefficient at the $5 \%$ significance level is not significant, but It can be considered that family social 
capital has a positive impact on the school support, just not significant. H3b hypothesis is close to being supported.

\section{Conclusions}

FSC---JS. According to the empirical results, we can draw a conclusion: the family social capital has significant influence on employment. From a practical perspective, it also can be demonstrated. In Chinese social networks, the parents will usually try to help their children find a good job after graduation. So the social status of parents, economic conditions, and contacts will have a significant impact on College Students' employment satisfaction[9,10]. And, based on experience, especially in the recruitment process of civil servants and state-owned enterprises, the family social capital has a significant positive impact on the employment of College graduates.

HC---JS. Through the empirical results of this paper, human capital does not have a significant positive impact on employment satisfaction, but there is a slight positive impact. This is different from our usual experience. Taking student leaders and rich practice can significantly enhance the college students' employment satisfaction, but the empirical results in this paper is not the case. Therefore, the author puts 3 inferences:

Student Cadres $\neq$ Improving the Ability. Now, some universities, some of the student cadres are bureaucracy and do not do their work, so the real work ability has not been much improved.

Most of the Internship Experience Fraud. Now, many students write a simple internship report, and then go to some units stamped. In fact, they did not really participate in the practice exercise, and therefore they did not improve their ability to work.

Heart Contrast. Although some graduate students spent more time to study and get a higher degree, due to the influence of other factors and improvement of self localization, some graduates' employment satisfaction are lower than the undergraduates'.

SS---JS. The empirical results of this paper show that school support of employment satisfaction has significant positive effect. Based on this, it can be seen that the school level can often determine what you are going to find work and many of the company's HR is like 985, 211 College graduates more than other college. On the other hand, the employment guidance of schools has a positive impact on job satisfaction of students.

\section{Reference}

[1] Javed H A, Jaffari A A, Rahim M, et al. Leadership Styles and Employees`Job Satisfaction: A Case from the Private Banking Sector of Pakistan[J]. Journal of Asian Business Strategy, 2017, 4:41-50.

[2] Unanue W, Gómez M E, Cortez D, et al. Revisiting the Link between Job Satisfaction and Life Satisfaction: The Role of Basic Psychological Needs:[J]. Frontiers in Psychology, 2017, 8.

[3] Brawley A M, Pury C L S. Work experiences on MTurk: Job satisfaction, turnover, and information sharing[J]. Computers in Human Behavior, 2016, 54:531-546.

[4] Hongisto V, Haapakangas A, Varjo J, et al. Refurbishment of an open-plan office Environmental and job satisfaction[J]. Journal of Environmental Psychology, 2016, 45:176-191.

[5] Macdonald J L, Levy S R. Ageism in the Workplace: The Role of Psychosocial Factors in Predicting Job Satisfaction, Commitment, and Engagement[J]. Journal of Social Issues, 2016, 72(1):169-190.

[6] Pan F C. Practical application of importance-performance analysis in determining critical job satisfaction factors of a tourist hotel.[J]. Tourism Management, 2015, 46:84-91.

[7] Gruneberg M M. Understanding Job Satisfaction[M]. Palgrave Macmillan UK, 1979.

[8] Montero R, Rau T. Relative Income and Job Satisfaction in Chile[M]// Handbook of Happiness Research in Latin America. Springer Netherlands, 2016:205-217.

[9] Małgorzata Rozkwitalska. Job Satisfaction and Subjective Well-Being in the Multicultural Workplace[M]// Intercultural Interactions in the Multicultural Workplace. Springer International Publishing, 2017. 
[10]Khamisa N, Peltzer K, Ilic D, et al. Work related stress, burnout, job satisfaction and general health of nurses: A follow-up study[J]. International Journal of Nursing Practice, 2016, 12(1):652. 